ECONOMICS

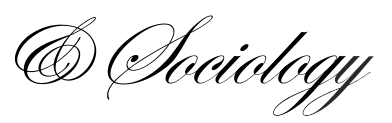

\title{
POSSIBILITY OF BUSINESS COOPERATION IN THE SELECTED ADRIATIC SEA PORTS
}

\author{
Mimo Draskovic \\ University of Montenegro, \\ Podgorica, Montenegor \\ E-mail:rookie@t-com.me \\ ORCID 0000-0003-0368-1934 \\ Radislav Jovovic \\ University of Mediterranean \\ Podgorica, Montenegro \\ E-mail:radejovovic@t-com.me

\section{Marcin Rabe \\ Faculty of Management and Economics of Services, University of Szcrecin, Szrzecin, Poland \\ E-mail:marcin.rabe@w,wieu.pl \\ ORCID 0000-0002-4817-1971}

Received: December, 2019

1st Revision: May, 2020

Accepted: September, 2020

DOI: $10.14254 / 2071-$

789X.2020/13-3/4
Draskovic, M., Jovovic, R., \& Rabe, M. (2020). Possibility of business

cooperation in the selected Adriatic Sea ports. Economics and Sociology, 13(3), 64-

71. doi:10.14254/2071-789X.2020/13-3/4

ABSTRACT. The subject of this paper is the analysis of perceptions of 210 respondents about the level of possible business cooperation between the three Adriatic seaports (Bar, Koper and Rijeka). The aim of the research is to assess the degree of negative impact of individual key influencing factors which are grouped in the model according to the principle of compatibility into three independent variables at the level of possible business cooperation (as dependent variables). It starts from the basic hypothesis that further development of these seaports, among other things, should be based on their greater business cooperation, because it can significantly increase their competitiveness (Juscius et al., 2020) in the wider region through better business and logistics competencies. The authors have also defined the auxiliary hypothesis that in order to establish the mentioned business cooperation, it is necessary to overcome many economic, political, institutional and other barriers (Gupta et al. 2019; Panikarova et al, 2020; Draskovic et al., 2020). The paper uses the method of multiple linear regression to determine the relationship between the dependent and the independent variables.

JEL Classification: L92, O18, Keywords: economic modeling, seaports, Koper, Rijeka, Bar. R49

\section{Introduction}

In this paper, the economic modeling was applied to the three selected Adriatic seaports (Koper, Rijeka and Bar), in which we conducted a field survey (the samples of 70 respondents in each of these seaports). The aim of the survey was to obtain valid answers, based on the perception of 210 respondents about the level of possible business cooperation between the selected Adriatic seaports of Koper, Rijeka and Bar, as well as about the possible negative impacts of the selected factors. In this sense, we have defined four basic research questions:

- What is the level of possible business cooperation between the seaports of Koper, Rijeka and Bar? - the dependent variable in the model; 
- What is the negative impact of institutional, infrastructural, suprastructural and corporate factors on the establishment of business cooperation in these seaports? - the first independent variable in the model;

- What is the negative impact of the applied level of logistics services on the establishment of business cooperation? - the second independent variable in the model;

- What is the negative impact of political and economic barriers on the establishment of business cooperation? - the third independent variable in the model.

To verify the initial and auxiliary hypotheses, in addition to theoretical considerations, we have used numerical tables, graphical and statistical analysis and regression multiple linear analysis on the data obtained in the course of surveying 210 respondents.

\section{Theoretical approach}

Many scientific papers (Misztal, 2010; Gonzalez \& Trujillo, 2009; Del Saz-Salazar and Garcia-Menendez, 2016; Draskovic, 2019) have directly and indirectly pointed out a number of factors that affect the level of development of seaports. Most of these factors negatively affect the possibilities of their regional connection, i.e. efficient business cooperation. A number authors pointed out infrastructure as the main constrain for establishing the high level of seaport cooperation. Baran and Górecka (2019) admitted that ineffective road and rails transportation in Croatia is a big constraint to a possible business model between seaports in Koper, Rijeka and Bar. Study of Vlahinić-Lenz et al., (2019) shows bad status of the transport infrastructure in Central and Eastern E.U. member states have negative effect on economic growth in these countries and consequently on seaports development. Many studies indicate the special role of infrastructure in locating foreign direct investments (FDI) (Brodzicki, Márquez-Ramos, \& Umiński, 2018; Dorożyński, Świerkocki, \& Urbaniak, 2018; Vu \& Ho, 2020). Entrepreneurial zones, established through public-private initiative and funded by EU funds attract more foreign direct investments (FDI) and that money can be used to improve the poor infrastructure of the Rijeka port (Kontošić-Pamić \& Belullo, 2018).

Based on the above research questions, which reflect the dependent variable and the three independent variables in the hypothetical model, we defined the research framework (Figure 1).

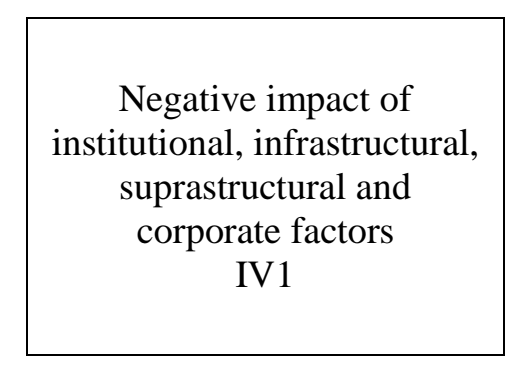

Figure 1. Research framework of the proposed hypothetical model Source: own creation

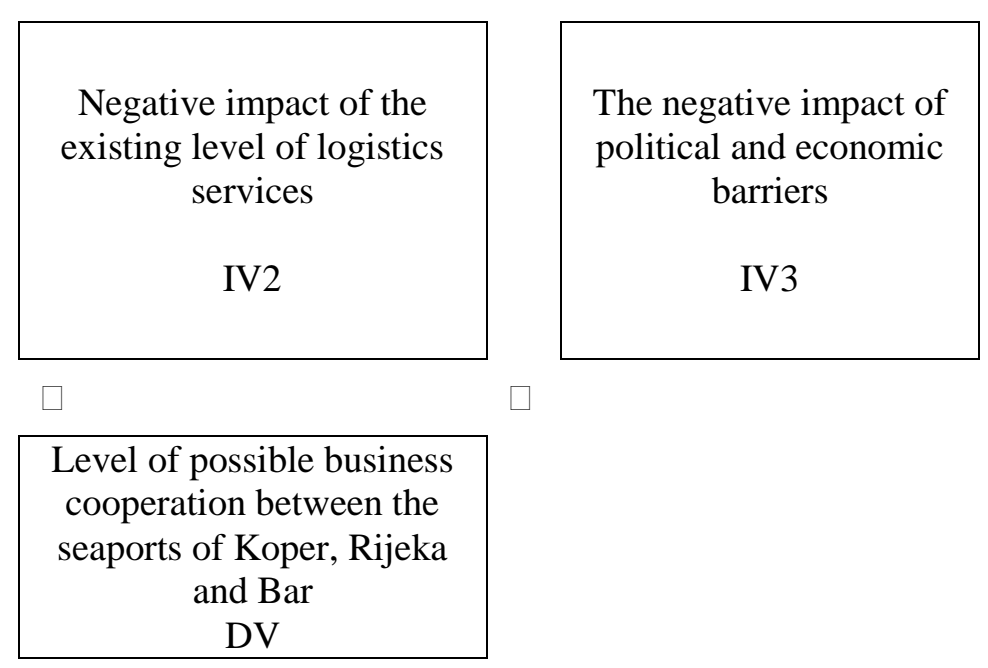


The initial research model connects three independent variables with one dependent variable. For the realization of multiple linear regression analysis, we used Modules Solver and SPSS (Coakes, 2013; Pallant, 2011; Teles \& Schachtebeck, 2019, Bayraktar, 2019). In addition, for simple mathematical statistical modeling, we used the works of N. Balakrishnan et al. (2007); D. Bertskas \& J. Tsitsiklis (2008). The constructs used in this study were measured on a Likert scale from 1 to 5 , where 1 means the least impact, and 5 the greatest impact. Multiple regression analysis was applied to the results of the respondents' perceptions obtained through the survey, for cases of specified ports.

\section{Conducting research and results}

Through the quantitative part of the research, the focus was on data collecting, processing, and explaining. According to the purpose defined in the hypothesis of work, descriptive statistics, the data analysis, correlation analysis, and multi-correlation method, were used for approval of it. The multiple linear regression model was applied after (the method of least square), as well as hierarchical multiple regression model.

\subsection{Multiple linear regression model}

Descriptive analysis of the obtained data at the level of perception of the respondents in the observed seaports showed that the conditions of normality and linearity for multiple regression were met. This essentially justifies the use of regression analysis of the first-order model. All extremes and atypical points were also checked. All of them satisfy the preconditions for the application of the multiple linear regression model for determining the linear relationship between the dependent variable and the independent variables. It is important to note that the correlation coefficient $(r)$ and the determination coefficient $(r 2)$ are quite large (Table 1). In this sense, they also justify the use of multiple linear regression models. Our goal was to determine the functional dependence between the levels of possible business cooperation (as a dependent variable - DV) and three independent variables $\left(I V_{1}, I V_{2}\right.$, $\left.I V_{3}\right)$ in the model: institutional, infrastructural, csuprastructural and corporate factors $\left(I V_{l}\right)$, applied level of logistics services $\left(I V_{2}\right)$, and political and economic barriers $\left(N P_{3}\right)$, respectively.

In addition, our goal was to determine the mean expected value of the dependent variable based on individual estimates of the respondents. Since the subjects evaluated the dependent $D V$ and independent variables $\left(I V_{1}, I V_{2}, I V_{3}\right)$ according to their subjective judgment (perception), our task was to determine the coefficients: $B_{0}, B_{1}, B_{2}$ and $B_{3}$, as well as to calculate using the next expression:

$$
\begin{gathered}
\overline{D V}=b_{0}+b_{1} \times I V_{1}+b_{2} \times I V_{2}+b_{3} \times I V_{3} \\
S S E=\sum_{k=1}^{n}\left(D V_{k}-\overline{D V} k\right)^{2}= \\
=\sum_{k=1}^{n}\left(D V_{k}-(B 0+B 1 * I V 1+B 2 * I V 2+B 3 * I V 3)\right)^{2}
\end{gathered}
$$

where is / are:

$\overline{D V}_{k}$ - the mean expected value of the dependent variable;

$B_{0}-$ section on the ordinate, determined on the basis of ascending data;

$B_{1}, B_{2}$ and $B_{3}$ - coefficients with the independent variables $I V_{1}, I V_{2}$ and $I V_{3}$, which in fact represent the slopes of the corresponding lines on the abscissa.

$n-$ is the total number of respondents (70 each from the ports of Bar, Koper and Rijeka). 
Based on these values, the value of the dependent variable can be calculated for each new value of the independent variable. It can be said that the mean value is based on the values of $I V_{1}, I V_{2}$, and $I V_{3}$. The least squares method was used to determine (Bertskas et al., 2008). a line minimizes the sum of the vertical differences for each pair of points by which those lines are determined In fact, our effort was to determine the coefficients: $B_{0}, B_{1}, B_{2}$ and $B_{3}$, in order to minimize the sum of the squares of the error (SSE).

\section{Results and discussion}

The advanced statistical software SPSS 23.0 was used for the realization of multiple linear regression analysis. In addition to the coefficients: $B_{0}, B_{1}, B_{2}$, and $B_{3}$, the following statistical indicators were determined: Mean absolute deviation (MAD), correlation coefficient $r$, coefficient of determination ( $r 2)$, Mean square error $(M S E)$, Mean absolute percent error $(M A P E)$ and Standard error of the regression estimate $(S E)$. The obtained results are shown in Table 1.

The following is a description of the statistical indicators shown in Table 1.

Mean absolute deviation (MAD) shows the extent to which the value of the dependent variable, obtained by multiple linear regression analysis, corresponds to the subjects' estimates. In other words, this statistical indicator speaks to the extent to which the model reflects respondents 'estimates. The specific values of the mean absolute deviation over the samples from the Port of Bar, the Port of Koper and the Port of Rijeka, are: 0,254, 0,337, 0,199 respectively. These values indicate a high correspondence of the model and the assessment of the respondents.

Table 1. Key parameters and statistical indicators in multiple linear regression model

\begin{tabular}{lccc}
\hline Parameter & $\begin{array}{c}\text { Case 1: } \\
\text { Port Bar }\end{array}$ & $\begin{array}{c}\text { Case 2: } \\
\text { Port Kopar }\end{array}$ & $\begin{array}{c}\text { Case 3: } \\
\text { Port Rijeka }\end{array}$ \\
\hline $\mathrm{B}_{0}$ & $-1,235$ & 1,201 & 0,191 \\
\hline $\mathrm{B}_{1}$ & 0,118 & 0,433 & 0,813 \\
\hline $\mathrm{B}_{2}$ & $-0,231$ & 0,357 & 0,045 \\
\hline $\mathrm{B}_{3}$ & 0,812 & 0,077 & 0,123 \\
\hline $\mathrm{R}$ & 0,687 & 0,710 & 0,659 \\
\hline $\mathrm{r}^{2}$ & 0,562 & 0,613 & 0,578 \\
\hline MAD & 0,254 & 0,337 & 0,199 \\
\hline MSE & 0,176 & 0,189 & 0,085 \\
\hline MAPE & $16,49 \%$ & $10,55 \%$ & $10,23 \%$ \\
\hline SE & 0,381 & 0,306 & 0,345 \\
\hline SOurce: & & &
\end{tabular}

Source: own creation

Mean square error (MSE) is the mean value of the square of the individual errors in the estimate. This is a deviation of: $0,176,0,189$, and 0,085 respectively, in the case of the analyzed samples from the Port of Bar, the Port of Koper and the Port of Rijeka. These numerous values also speak in favor of satisfactory compliance of the model with real data, collected through questionnaires.

Mean absolute percent error (MAPE) is the percentage of error in estimating the value of a dependent variable by respondents and based on the model. It is the simplest statistical quantity in terms of interpretation. In the case of our research, it takes the values: $16,49 \%$, $10,55 \%, 10,23 \%$, and $10.23 \%$, respectively, for the cases of the analyzed questionnaires from the Port of Bar, the Port of Koper and the Port of Rijeka. These values also indicate an appropriate level of correspondence between models and respondents' estimates. 
The standard error of the regression estimate $(S E)$ is also called the standard deviation of the regression. This statistical quantity is suitable for the formation of the so-called confidence interval around the regression line. It shows how much the dependent variable, obtained by the model, can vary. In our study, the standard deviation has the following values: in the case of the sample from the Port of Bare 381, the Port of Koper. 0,306, and the Port of Rijeka 0,345.

According to the data given in Table 1, the lines representing the functional dependence between the dependent and independent variables $\left(I V_{l-3}\right)$ are given below.

\section{Case 1: Port Bar(PB):}

$$
\begin{aligned}
& \overline{D V}_{P B}=b_{0}+b_{1} \times I V_{1}+b_{2} \times I V_{2}+b_{3} \times I V_{3} \\
& \overline{D V_{P B}}=-1,235+0,118 \times I V_{1}-0,231 \times I V_{2}+0,812 \times I V_{3}
\end{aligned}
$$

\section{Case 2: Port Kopar (PK)}

$$
\begin{aligned}
& \overline{D V}_{P K}=b_{0}+b_{1} \times I V_{1}+b_{2} \times I V_{2}+b_{3} \times I V_{3} \\
& \overline{D V}_{P K}=1,201+0,433 \times I V_{1}+0,357 \times I V_{2}+0,077 \times I V_{3}
\end{aligned}
$$

\section{Case 3. Port Rijeka (PR)}

$$
\begin{aligned}
& \overline{D V_{P R}}=b_{0}+b_{1} \times I V_{1}+b_{2} \times I V_{2}+b_{3} \times I V_{3} \\
& \overline{D V_{P R}}=1,191+0,813 \times I V_{1}+0,045 \times I V_{2}+0,123 \times I V_{3}
\end{aligned}
$$

The expected mean value of the dependent variable was calculated based on the previous equations and the following results were obtained:

\begin{tabular}{ccc}
\hline Port Bar & Port Kopar & Port Rijeka \\
\hline 2,61 & 3,07 & 3,56 \\
\hline
\end{tabular}

According to the analysis of the linear dependence between the dependent variable and the mean values of the independent variables at the level of all ports (Figure 2), it is clear that the variable $I V_{l}$ has the most pronounced influence on the dependent variable. Then variable $I V_{2}$, and then $I V_{3}$. These analyzes were done over the entire sample. The rank of influence in individual ports is the similar. Based on the analysis of the individual sample in the considered seaports, the rank of the influence of the independent on the dependent variable given in Table 2 was obtained.

In accordance with the mean values of the independent variables (Table 2), it can be concluded that the greatest limitations in terms of the level of possible business-partnership cooperation characterize the seaport of Bar. This is understandable, given that the most pronounced negative impact of the observed factors (independent variables), where it is most pronounced in the institutional, infrastructural, suprastructural and corporate factors $\left(I V_{l}\right)$, as well as the negative impact of the existing level of logistics services $\left(I V_{2}\right)$, while the negative impact of political and economic barriers $\left(I V_{3}\right)$ is moderate.

At the seaport of Koper, the smallest perceptual limitations in terms of businesspartnership cooperation were identified, ie the greatest perceptual possibilities. The preperformance resulted from the fact that it is characterized by the least negative influences on all tree independent variables. Nevertheless, it is noticeable that the greatest negative impact was shown in infrastucture $\left(I V_{1}\right)$ and logistic $\left(I V_{2}\right)$, and the least in political and economic barriers $\left(I V_{3}\right)$. 




Figure 2. Dependencies between the dependent variable and the mean values of the independent variables at the level of all observed Adriatic seaports

Source: own creation

Table 2. Mean values of independent variables $\left(I_{1-3}\right)$ and the rank of their impact on the dependent variable $(D V)$

\begin{tabular}{llll}
\hline Rank & Case 1: Port Bar & Case 2: Port Kopar & Case 3: Port Rijeka \\
\hline 1 & $\mathrm{IV}_{1}[4,41]$ & $\mathrm{IV}_{1}[3,11]$ & $\mathrm{IV}_{1}[3,84]$ \\
\hline 2 & $\mathrm{IV}_{2}[3,71]$ & $\mathrm{IV}_{2}[3.05]$ & $\mathrm{IV}_{2}[3,02]$ \\
\hline 3 & $\mathrm{IV}_{3}[2,92]$ & $\mathrm{IV}_{3}[2,20]$ & $\mathrm{IV}_{3}[2,56]$ \\
\hline
\end{tabular}

Source: own

On the other hand, at the seaport of Rijeka, moderate perceptual negative influences were manifested in terms of the level of possible business-partnership cooperation. They are significantly smaller (more favorable) in relation to the seaport of Bar, but they are also partially larger (less favorable) in relation to the seaport of Koper.

\section{Conclusion}

In the theoretical part of this paper, three factors have been identified, which have a dominant negative impact on the establishment of business cooperation between the considered Adriatic seaports of Bar, Koper and Rijeka. In the empirical part of the paper, a strong connection was found between the independent variables and the dependent variable. The results of the research and their analysis confirmed that their influence is different in the considered seaports, but that in all of them at a certain level it has a negative effect on the dependent variable.

The statistical analysis of the data showed that there is a linear relationship between the dependent variable and the independent variables. Multiple linear regression analysis determined the functional relationship between the dependent variable and the three independent variables. The set relationship model enables the prediction of a change in the level of business cooperation if some or all of the independent variables change. It was confirmed that the independent variables largely explain the relatively low level of possible business cooperation between the considered seaports. Thus, the perception of the 
respondents and the results obtained after statistical data processing show the correctness of the initial hypothesis of the work, as well as the auxiliary hypothesis.

Empirical hypothetical research, conducted through a survey of 210 respondents (70 in each of these seaports) showed that the greatest limitations in terms of the level of possible business-partnership cooperation characterize the seaport of Bar. This is due to the fact that it has the most pronounced negative impact of the two observed factors (independent variables),

At the seaport of Koper, survey research and analysis identified the smallest perceptual limitations in terms of business-partnership cooperation, i.e. the greatest perceptual possibilities. It is anterior because it is characterized by the smallest negative influences on all four independent variables.

At the seaport of Rijeka, moderate perceptual negative influences were manifested in terms of the level of possible business-partnership cooperation. They are significantly smaller (more favorable) in relation to the seaport of Bar, but they are also partially larger (less favorable) in relation to the seaport of Koper. The analyzes showed that the largest (but also approximate) negative impact was shown by the infrastructural factors $\left(I V_{l}\right)$.

These conclusions point to the general conclusion that in all the considered Adriatic seaports it is necessary to invest large investment, organizational and other efforts in order to improve certain factors influencing the dependent variable. This is especially true of the Montenegrin seaport of Bar.

In the theoretical part of this paper, three factors have been identified, which have a dominant negative impact on the establishment of business cooperation between the considered Adriatic seaports of Bar, Koper and Rijeka. In the empirical part of the paper, a strong connection was found between the independent variables and the dependent variable. The results of the research and their analysis confirmed that their influence is different in the considered marine figures, but that in all of them at a certain level it has a negative effect on the dependent variable.

\section{References}

Balakrishnan, N., Render, B., \& Stair, R.M. (2007). Managerial Decision Modeling with Spreadsheets, New Jersey: Prentice-Hall Inc.

Baran, J., \& Górecka, A.K. (2019). Economic and environmental aspects of inland transport in EU countries, Economic Research-Ekonomska Istraživanja, 32(1), 1037-1059, https://doi.org/10.1080/1331677X.2019.1578680

Bayraktar, N., (2019). Effectiveness of public investment on growth in sub-Saharan Africa. Eurasian Economic Review, 9(4), pp.421-457.

Bertskas, D.P., \&Tsitsiklis, J.N. (2008). Introduction to probability, USA: Athena Scientific.

Brodzicki, T., Márquez-Ramos, L., \& Umiński, S. (2018). The Investigation into Determinants of Regional Exports Base: Panel Analysis for Spanish and Polish Regions. Entrepreneurial Business and Economics Review, 6(1), 135-151. https://doi.org/10.15678/EBER.2018.060108

Coakes, S.J. (2013). SPSS 20.0 for Windows - Analysis without Anguish, Willey Publishing, Inc.

Dorożyński, T., Świerkocki, J., \& Urbaniak, W. (2018). Determinants of Investment Attractiveness of Polish Special Economic Zones. Entrepreneurial Business and Economics Review, 6(4), 161-180. https://doi.org/10.15678/EBER.2018.060409

Draskovic, M. (2019). Perception of the Impact of Negative Externalities on the Logistics Development of Adriatic Seaports of Koper, Rijeka and Bar. Amfiteatru Economic, 21(50), 228-239. 
Draskovic, V., Jovovic, J., Streimikiene, D., Bilan, S. (2020). Formal and Informal vs. Alternative Institutions. Montenegrin Journal of Economics, 16(2), 193-201.

Gonzalez, M.M., Trujillo, L. (2009). Efficiency measurement in the port industry: A survey of the empirical evidence". Journal of Transport Economics and Policy, 43(2), 157-192.

Gupta, R., Gozgor, G., Kaya, H., \& Demir, E., 2019. Effects of geopolitical risks on trade flows: evidence from the gravity model. Eurasian Economic Review, 9(4), pp.515-530.

Juscius, V., Bogatova, J., \& Draskovic, M. (2020). Evaluation Framework of Seaports' Competitiveness Increasing Projects. Montenegrin Journal of Economics, 16(2), 49-58.

Kontošić-Pamić, R., \& Belullo, A. (2018). Investments' background of entrepreneurial zones in Croatia, Economic Research-Ekonomska Istraživanja, 31(1), 1590-1606, https://doi.org/10.1080/1331677X.2018.1506707

Mardani, A., Jusoh, A., Halicka, L., Ejdys, J., Magruk, A., Ahmad, U.N.U. (2018). Determining the utility in management by using multi-criteria decision support tools: a review, Economic Research-Ekonomska Istraživanja, 31(1), 1666-1716, https://doi.org/10.1080/1331677X.2018.1488600

Misztal, K. (2010). Organization and operation of sea ports, Gdansk: Gdansk University (in Poland).

Pallant, J. F. (2011). SPSS Survival Manual: A Step by Step Guide to Data Analysis Using SPSS, Australia: Allen \& Unwin.

Panikarova, S., Vlasov, M., \& Draskovic, M. (2020). Relationsheep between Social Business Entrepreneurship and Business Freedom: an Evidence from the Russian. Montenegrin Journal of Economics, 16(3), 123-136.

Del Saz-Salazar, S., \& Garcia-Menendez, L. (2016). Port Expansion and Negative Externalities: A Willingness to Accept Approach. Maritime Policy \& Management, 43, 59-83.

Teles, D., \& Schachtebeck, C. (2019). Entrepreneurial Orientation in South African Social Enterprises. Entrepreneurial Business and Economics Review, 7(3), 83-97. https://doi.org/10.15678/EBER.2019.070305

Vlahinić-Lenz, N., Pavlić-Skender, H., \& Adelajda-Mirković, P. (2018). The macroeconomic effects of transport infrastructure on economic growth: the case of Central and Eastern E.U. member states, Economic Research-Ekonomska Istraživanja, 31(1), 1953-1964, https://doi.org/10.1080/1331677X.2018.1523740

Vu, D., \& Ho, T. (2020). Provincial Foreign Direct Investment Absorptive Capacity of Vietnam. Entrepreneurial Business and Economics Review, 8(2), 7-26. https://doi.org/10.15678/EBER.2020.080201 